\title{
Award winning paper in 2017
}

Papers published in Urban Design and Planning are eligible for awards from the Institution of Civil Engineers. Papers from any of the ICE journals can be nominated for several awards. In addition, each journal has awards dedicated to their specific subject area.

On Monday 8 October 2018, ICE president Professor Lord Robert Mair presented an award to the following paper published in Urban Design and Planning in 2017.

The editorial panel nominated their best papers and an awards committee chaired by Nigel Wright allocated the awards.

\section{Reed and Mallik Medal}

The Reed and Mallik Medal, presented for the best paper published in Urban Design and Planning, was awarded to Nijhuis et al. (2017).

\section{Abstract}

The Department of Urbanism at the Faculty of Architecture and Built Environment at the Delft University of Technology has a long tradition in educating generations of internationally oriented designers, planners and researchers in urbanism. Here the domain of urbanism is defined as an interdisciplinary approach that engages in real-world sociocultural, ecological and technological issues affecting urban landscapes, from the perspective of spatial planning and design. Specifically, it combines the disciplines of spatial planning, urban design and landscape architecture, having their own theories, methods and techniques, but also sharing common grounds and being complementary. Urbanism education focuses on specific context-related design tasks, in which knowledge from different disciplines is synthesised into coherent multiscale proposals. This paper aims to elaborate on the foundations of the Delft approach to urbanism education that focuses on the urban landscape as a scale continuum, uses design research and research through design as important teaching and research strategies, and regards mapping and drawing as important tools for thinking. The typical Dutch geographic context and spatial planning traditions are the foundation for this approach. The paper addresses the backgrounds and describes the principles of the present education strategies, learning tactics and examination, and identifies their challenges.

\section{REFERENCE}

Nijhuis S, Stolk E and Hoekstra M (2017) Teaching urbanism: the Delft approach. Proceedings of the Institution of Civil Engineers - Urban Design and Planning 170(3): 96-106, https://doi.org/10.1680/ jurdp.16.00013.

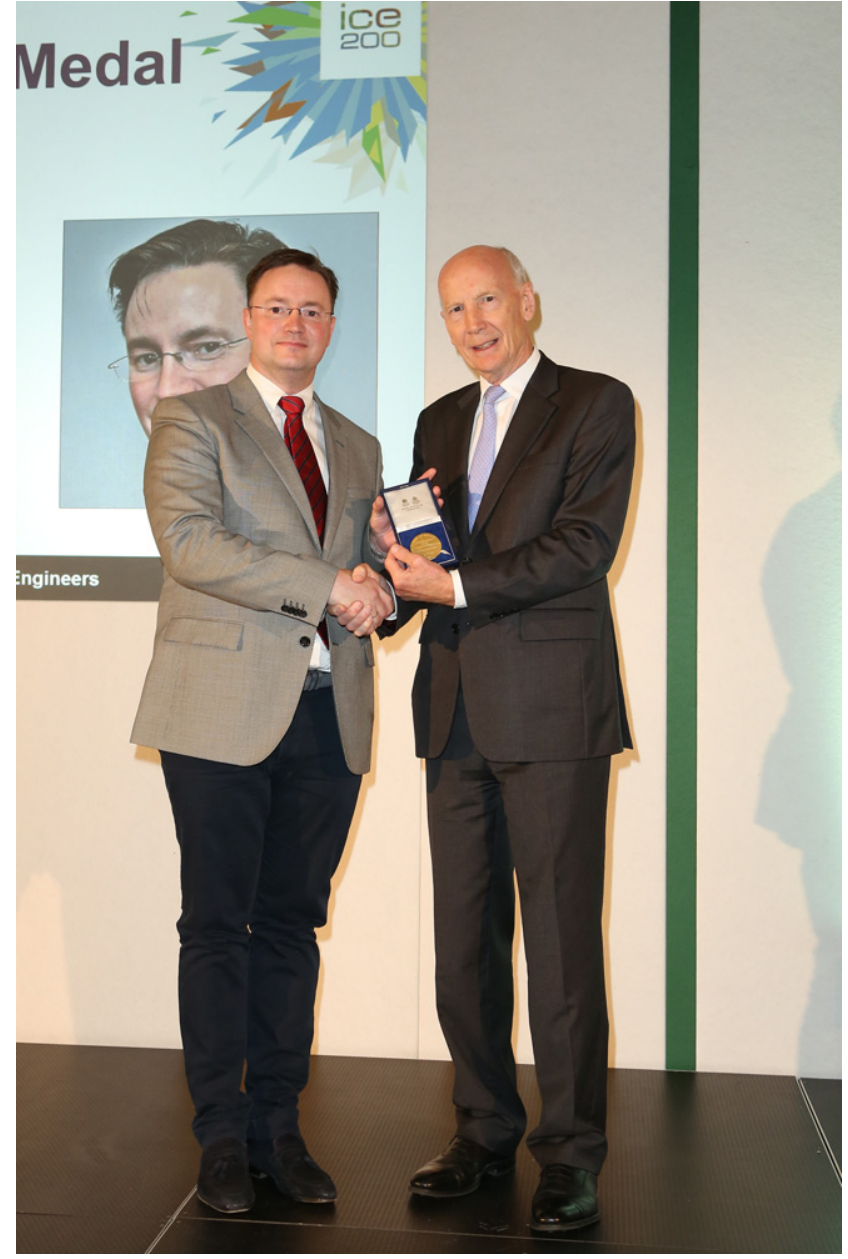

Winners of the Reed and Malik Prize, with ICE President Professor Lord Robert Mair 